\title{
Proportion of Cesarean Deliveries According to Hospital Funding in São Paulo Metropolitan Area, Brazil
}

\author{
Priscila Ribeiro Raspantini' ${ }^{1}$, Zilda Pereira da Silva ${ }^{1}$, Gizelton Pereira Alencar ${ }^{1}$, \\ Bárbara Laisa Alves Moura ${ }^{1}$, Felipe Parra do Nascimento ${ }^{2}$, Laura Cunha Rodrigues 3 , \\ Patrícia Carla dos Santos ${ }^{1}$, Marcia Furquim de Almeida ${ }^{1}$ \\ ${ }^{1}$ School of Public Health at University of São Paulo, São Paulo, Brazil \\ ${ }^{2}$ Medical School at University of São Paulo, São Paulo, Brazil \\ ${ }^{3}$ London School of Hygiene and Tropical Medicine, London, UK \\ Email: priscilarasp@gmail.com
}

Received 29 September 2015; accepted 27 November 2015; published 30 November 2015

Copyright @ 2015 by authors and Scientific Research Publishing Inc.

This work is licensed under the Creative Commons Attribution International License (CC BY). http://creativecommons.org/licenses/by/4.0/

(c) (7) Open Access

\begin{abstract}
Introduction: There has been an increase in the proportion of cesarean deliveries, especially in developing countries. Methods: Cross-sectional study of all hospital live births from mothers living in São Paulo Metropolitan Area, Brazil. Data were obtained from the Live Birth Information System, which is linked to the National Database of Health Establishments. Hospitals were classified as public, private or mixed. Descriptive analysis and exponential regression were conducted to evaluate time trends. Poisson regression was applied to analyze each hospital type to identify risk factors and the attributable risk fraction for cesarean section. Results: There was an annual increase $(1.4 \%)$ of cesarean deliveries between 2000 and 2013. In 2009, the percentage of cesarean deliveries was $53 \%$ overall and $83 \%$ in private hospitals. The primary risk factor for cesarean delivery was delivery in a private hospital. Other risk factors that were stronger in public hospitals included the following: advanced maternal age, high maternal education, nulliparity, high number of prenatal visits, multiple pregnancy, hospital with low annual volume of deliveries, birth outside the city of residence and white skin color. Discussion: These results may be explained by the obstetric care model of private hospitals, which is not multiprofessional. Prenatal care and delivery are conducted by the same doctor and rarely include the input of another professional, such as a midwife. In addition, the mode of delivery influences the professional's payment.
\end{abstract}

\section{Keywords}

Cesarean Sections, Risk Factors, Public, Private and Mixed Hospitals, Poisson Regression 


\section{Introduction}

The increase in the proportion of cesarean sections in recent decades is a public health problem, especially in developing countries [1]. A cesarean section is a surgical procedure that increases the risk of maternal and neonatal morbidities [2], and the cost of delivery care [3]. Genuine need due to maternal clinical conditions does not explain the high rates found in Brazil, where almost $45 \%$ of all deliveries were by cesarean section [4]. The high frequency of cesarean sections has been partly attributed to the increasing number of elective cesareans [5]. A recent study showed that $27.5 \%$ of Brazilian women had an initial preference for cesarean delivery [6]. This high cesarean preference was not found in other places in a recent meta-analysis study [7].

Some studies showed that the hospital funding and obstetrical practices can influence the proportion of cesarean deliveries [8]. The Brazilian Health System is composed of providers and users of public and private services [9], and it is possible to identify delivery-care providers as public, mixed or private hospitals. Public hospitals are financed and provided by the state through the Unified Health System, which is free of charge to patients. Mixed hospitals are financed by public (Unified Health System) and private resources (for-profit and non-profit organizations). The financial resources of mixed hospitals are mostly provided by private insurance/ health plans. Private hospitals are funded from direct reimbursement or by different types of private insurance/ health plans. The public and private components of the system are distinct but interconnected, and patients can use the services of all three types of hospitals depending on ease of access or their ability to pay [9].

There is some evidence that the proportion of cesarean deliveries is higher in private hospitals in Brazil [8] independent of the clinical condition of the pregnant woman or the number of births carried out in these hospitals. However, even though the proportion of cesarean deliveries is lower in public hospitals [2], it is still higher than the $15 \%$ recommended by the WHO [10].

In addition to the type of hospital funding, some characteristics of the mothers can also influence the incidence of cesarean sections, such as advanced maternal age [11], high maternal education [11] [12], nulliparity [11], and previous cesarean section [13]. The clinical conditions [11], some cultural aspects [14], and the organization of the obstetric practice [15] can also influence cesarean sections. Tubal ligation [16] has also been related to higher cesarean rates in Brazil. Tubal ligation at the time of delivery was banned by public health services, with an exception for women with a high number of previous cesarean deliveries [16].

This study evaluated the temporal tendency of cesarean sections in the metropolitan area of São Paulo and identified risk factors for cesarean births per type of hospital for 2009.

\section{Methodology}

The area of the study was the Sao Paulo Metropolitan area in Brazil, the largest Latin American metropolis with a population of 19,683,975 inhabitants. It is the financial and economic center of Brazil, with per capita income of US $\$ 17,852$, in 2009. It has the largest and most complex health care system in the country [17].

We analyzed the births to mothers living in the São Paulo Metropolitan area by two approaches: using aggregate data and individualized data. Exponential regression analysis was carried out to evaluate the time trend of cesarean section rates from 2000 to 2013. Information was obtained from the aggregate data on live births available on the Electronic National System of Information on Live Births dataset [18] (Figure 1).

Individual database of live births was necessary to link with National Data Base of Health Establishments of Brazilian Ministry of Health to obtain the type of hospital of birth. The individualized data set was obtained from Live Birth Certificates of live births from January 1 to December 31, 2009. It was used the unified database provided by SEADE Foundation/São Paulo State Health Department. These data were linked to the hospital where the birth occurred by National Data Base of Health Establishments of the Brazilian Ministry of Health. The hospital code is found in Live Birth Certificates and the Brazilian National Data Base of Health Establishments.

It was carried out a cross sectional analysis with linked individual data of live births in 2009. Data on live births included the following: for the mother, age, maternal education and parity (number of prior living births and fetal deaths); type of pregnancy (single/multiple); number of prenatal visits and for the infant, gestational age, race/skin color. Information on hospitals where the live births were delivered was obtained from the Brazilian National Data Base of Health Establishments. The hospitals were classified as public if they had exclusive public financing; mixed if financed by public and private resources; and private if they had exclusive private financing. 
The cross sectional analysis was conducted for 2009 only rather than for the entire period because the hospital code was only recently made available in Live Birth Certificates, so the linkage of births to hospitals is not possible for prior years. Hospitals were categorized according to the volume of births as those with fewer than 1000 or 1000 or more deliveries a year. Deliveries were categorized into those occurring in hospitals in the city of residence of the mother or in other municipalities within the Sao Paulo Metropolitan area.

The following births were excluded from the analysis: 52 in which the hospital could not be identified; 1448 births not in a hospital, and 155 with no information as to the type of delivery. These exclusions accounted for $0.65 \%$ of the live births. The completeness of the variables studied was over $95 \%$.

The proportion of cesarean deliveries per category of the explanatory variables was calculated, and a trend test was performed. Due to the high prevalence ratios, we used Poisson regression with robust variance for the binary response variable "type of delivery", calculating the prevalence ratio and 95\% confidence intervals (CI) [19]. The stepwise model-building strategy was applied by the insertion of variables for delivery providers. The attributable risk fraction was calculated based on the adjusted prevalence ratio for each category of exposure variables [20]. Models were then selected for type of financing at the place of delivery. We used Stata, version 10.0 for statistical analysis.

The project was approved by the Research Ethic Committee of the School of Public Health of University of São Paulo. This study was funded by a grant from PAHO (Pan-American Health Organization) and the Sao Paulo State Health Department.

\section{Results}

Graph 1 presents the data on the proportion of cesarean deliveries over fourteen years in the São Paulo Metropolitan area. In 2000, the rate was $46.3 \%$, and in 2013 it reached 56\%, which represents a statistical significant increase of $1.4 \%$ a year.

A total of 305,167 live births in the São Paulo Metropolitan area in 2009 were studied. Of these, 81.1\% $(247,597)$ births occurred in the city in which the mother lived, $18.9 \%(57,570)$ outside of the municipality of residence, and only $0.6 \%$ in cities in other regions of the State of São Paulo. These births took place in 167 hospitals in the Sao Paulo Metropolitan area.

The proportion of births by cesarean was of $32 \%$ in public hospitals, $44 \%$ in mixed hospitals, and $82 \%$ in private hospitals. All variables had a statistically significant effect and remained in the final model (Table 1). The proportion of cesarean section deliveries is determined mostly by type of hospital funding and minimally by the

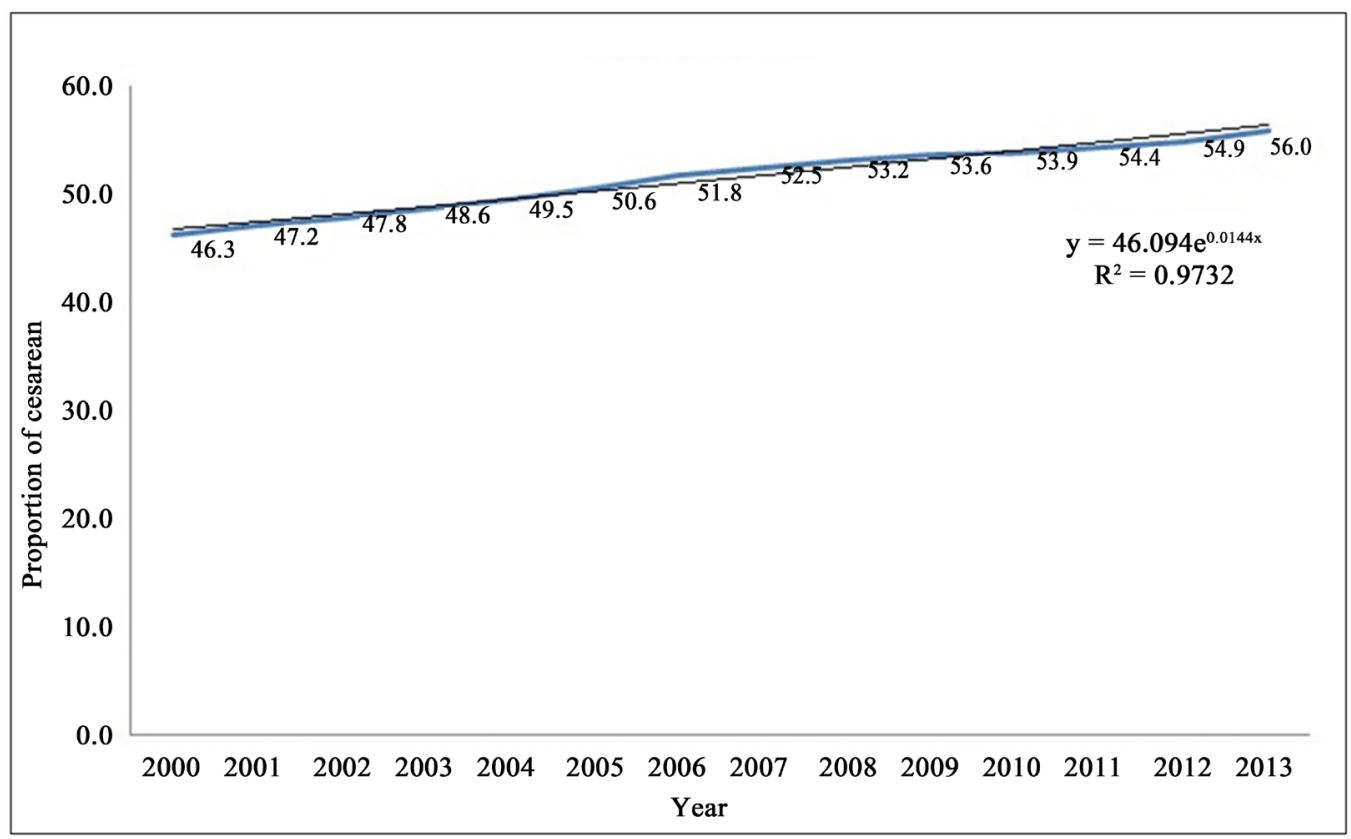

Figure 1. Proportion of cesarean deliveries in hospital births (\%) in the São Paulo Metropolitan Area, 2000 to 2013. 
Table 1. Number of live births, proportion of cesarean deliveries, crude and adjusted prevalence ratio (95\% confidence interval), and confidence interval, according to maternal, newborn and hospital’s characteristics. São Paulo Metropolitan Area, 2009.

\begin{tabular}{|c|c|c|c|c|c|c|}
\hline Variables & $\mathbf{N}$ & \% cesarean & $\begin{array}{l}\text { Prevalence ratio } \\
\text { (crude) }\end{array}$ & $\mathbf{C I}^{1}$ & $\begin{array}{l}\text { Prevalence ratio } \\
\text { (adjusted) }\end{array}$ & $\mathbf{C I}^{2}$ \\
\hline \multicolumn{7}{|l|}{ Type of hospital } \\
\hline Public & 149,800 & 32.1 & 1 & & 1 & - \\
\hline Mixed & 38,583 & 44.4 & 1.38 & $1.35-1.41$ & 1.31 & $1.28-1.33^{*}$ \\
\hline Private & 116,784 & 82.7 & 2.58 & $2.54-2.62$ & 2.20 & $2.17-2.23^{*}$ \\
\hline \multicolumn{7}{|l|}{ Mother's age (years) } \\
\hline$\leq 19$ & 43,293 & 32.2 & 0.40 & $0.39-0.41$ & 0.74 & $0.72-0.76$ \\
\hline 20 to 34 & 219,317 & 54.4 & 1 & & 1 & - \\
\hline$\geq 35$ & 42,557 & 68.3 & 1.81 & $1.77-1.85$ & 1.17 & $1.15-1.18$ \\
\hline \multicolumn{7}{|l|}{ Maternal education (years) } \\
\hline$<4$ & 62,536 & 38.1 & 1 & & 1 & - \\
\hline 4 to 11 & 180,394 & 50.4 & 1.23 & $1.21-1.25$ & 1.02 & $1.00-1.04^{*}$ \\
\hline$\geq 12$ & 60,574 & 77.0 & 1.99 & $1.59-1.61$ & 1.05 & $1.03-1.07^{*}$ \\
\hline \multicolumn{7}{|l|}{ Parity } \\
\hline Nulliparous & 133,820 & 57.4 & 1.28 & $1.26-1.30$ & 1.09 & $1.07-1.11$ \\
\hline Multiparous & 142,441 & 51.3 & 1 & & 1 & - \\
\hline Grand multiparous & 14,612 & 33.6 & 0.48 & $0.46-0.50$ & 0.83 & $0.80-0.86$ \\
\hline \multicolumn{7}{|l|}{ Newborn skin color } \\
\hline White & 206,764 & 58.3 & 1.89 & $1.86-1.92$ & 1.05 & $1.04-1.06$ \\
\hline Non-white & 98,403 & 42.4 & 1 & & 1 & - \\
\hline \multicolumn{7}{|l|}{ Pregnancy } \\
\hline Single & 297,717 & 52.3 & 1 & & 1 & - \\
\hline Multiple & 7450 & 87.3 & 1.67 & $1.65-1.68$ & 1.48 & $1.44-1.52$ \\
\hline Gestational age (weeks) & & & & & & - \\
\hline$<37$ & 27,119 & 58.4 & 1.26 & $1.23-1.30$ & 1.03 & $1.01-1.05$ \\
\hline$\geq 37$ & 278,404 & 52.7 & 1 & & 1 & - \\
\hline \multicolumn{7}{|l|}{ Number of prenatal visits } \\
\hline$\leq 3$ & 16,367 & 27.5 & 1 & & 1 & - \\
\hline 4 to 6 & 63,646 & 39.1 & 1.30 & $1.26-1.34$ & 1.23 & $1.18-1.28^{*}$ \\
\hline$\geq 7$ & 223,831 & 59.1 & 1.72 & $1.67-1.77$ & 1.37 & $1.33-1.41^{*}$ \\
\hline \multicolumn{7}{|c|}{ Volume of hospital births (births/year) } \\
\hline$\leq 1000$ & 28,750 & 66.6 & 1.29 & $1.26-1.33$ & 1.12 & $1.10-1.13$ \\
\hline$>1000$ & 276,417 & 51.8 & 1 & & 1 & - \\
\hline \multicolumn{7}{|l|}{ Hospital location } \\
\hline In the city of residence & 247,597 & 50.3 & 1 & & 1 & - \\
\hline Outside the city of residence & 57,570 & 65.6 & 1.30 & $1.27-1.33$ & 1.04 & $1.02-1.06$ \\
\hline Total & 305,167 & 53.2 & & & & \\
\hline
\end{tabular}

${ }^{*}$ Trend test $<0.001 ;{ }^{* *}$ Adjusted Poisson regression with all variables. $\mathrm{CI}^{1}$ : Crude; $\mathrm{CI}^{2}$ : Adjusted.

other risk factors. A higher proportion of cesareans was observed among births in private and mixed hospitals; hospitals with fewer births; to mothers aged 35 years or more, with high maternal education, nulliparous, with seven or more prenatal visits; with multiple pregnancies, white newborns, preterm births and births outside the city of the mother's residence (Table 1).

Table 1 shows that after adjustment for the other variables, cesarean section delivery remained more likely in private hospitals, multiple pregnancies and to mothers who had seven or more prenatal visits. It was also less likely in young women ( $\leq 19$ years) and those with $\geq 4$ previous children. Estimates for all of the analyzed va- 
riables changed strongly when adjusted for type of hospital funding; the effect was stronger for maternal education and white newborns and weakest for multiple pregnancies. The variables assessing the structure of health services, such as attending 7 prenatal visits or more, the annual volume of births being lower than 1000, and birth outside the municipality of residence remained risk factors for cesarean sections. With regard to prenatal visits, there was a growing likelihood of cesarean births with increasing number of prenatal visits.

Table 2 presents the adjusted models for cesarean births in public, mixed and private hospitals. Due to the high proportion of cesarean deliveries in private hospitals, maternal, gestational and newborn characteristics make a small contribution to the risk of cesarean sections. In private hospitals, teenage mothers and the high number of multiparous women maintained their protective effect against the performance of cesarean sections. Only the increasing number of prenatal visits and the presence of multiple pregnancies increased the chances of cesarean sections more than $15 \%$, while the contribution of the other variables for this type of birth was between $2 \%$ to $7 \%$.

Table 2. Proportion and prevalence ratio (95\% confidence interval) of cesarean deliveries according to maternal, newborn and hospital characteristics by type of hospital. São Paulo Metropolitan Area, 2009.

\begin{tabular}{|c|c|c|c|c|c|c|}
\hline \multirow{3}{*}{ Variable } & \multicolumn{3}{|c|}{$\%$ cesarean } & \multicolumn{3}{|c|}{ Type of hospital } \\
\hline & Public & Mixed & Private & PR (CI 95\%) & PR (CI 95\%) & PR (CI 95\%) \\
\hline & $32.1 \%$ & $44.4 \%$ & $82.7 \%$ & Public & Mixed & Private \\
\hline \multicolumn{7}{|l|}{ Mother's age (years) } \\
\hline$\leq 19$ & 23.5 & 34.7 & 73.0 & $\mathbf{0 . 6 7}(0.65-0.69)^{*}$ & $\mathbf{0 . 7 3}(0.69-0.77)^{*}$ & $\mathbf{0 . 8 9}(0.86-0.92)^{*}$ \\
\hline 20 to 34 & 32.7 & 44.7 & 82.6 & 1 & 1 & 1 \\
\hline 35 and older & 44.7 & 57.3 & 87.5 & $1.45(1.41-1.48)^{*}$ & $1.37(1.31-1.44)^{*}$ & $\mathbf{1 . 0 7}(1.05-1.09)^{*}$ \\
\hline \multicolumn{7}{|l|}{ Schooling (years) } \\
\hline$<4$ & 31.3 & 40.4 & 76.1 & 1 & 1 & 1 \\
\hline 4 to 11 & 31.6 & 44.5 & 81.2 & $\mathbf{0 . 9 9}(0.97-1.01)^{* *}$ & $1.07(1.02-1.11)^{*}$ & $\mathbf{1 . 0 4}(1.01-1.07)^{*}$ \\
\hline 12 and more & 40.3 & 53.9 & 86.7 & $1.13(1.08-1.17)^{* *}$ & $\mathbf{1 . 1 7}(1.10-1.25)^{*}$ & $1.07(1.04-1.10)^{*}$ \\
\hline \multicolumn{7}{|l|}{ Parity } \\
\hline Nulliparous & 32.5 & 43.6 & 81.4 & $\mathbf{1 . 1 8}(1.15-1.21)^{*}$ & $1.09(1.05-1.13)^{*}$ & $\mathbf{1 . 0 5}(1.04-1.07)^{*}$ \\
\hline Multiparous & 32.0 & 43.9 & 85.1 & 1 & 1 & 1 \\
\hline Grand multiparous & 28.5 & 34.9 & 63.7 & $\mathbf{0 . 8 0}(0.77-0.83)^{*}$ & $\mathbf{0 . 7 5}(0.70-0.82)^{*}$ & $\mathbf{0 . 8 0}(0.75-0.85)^{*}$ \\
\hline \multicolumn{7}{|l|}{ NB's color } \\
\hline White & 32.9 & 46.8 & 84.1 & $1.03(1.02-1.05)^{*}$ & $\mathbf{1 . 1 5}(1.09-1.19)^{*}$ & $\mathbf{1 . 0 5}(1.03-1.06)^{*}$ \\
\hline Non-white & 31.2 & 38.9 & 78.4 & 1 & 1 & 1 \\
\hline \multicolumn{7}{|l|}{ Pregnancy } \\
\hline Single & 31.2 & 43.5 & 82.6 & 1 & 1 & 1 \\
\hline Multiple & 78.2 & 83.8 & 96.1 & $2.21(2.11-2.31)^{*}$ & $1.72(1.57-1.88)^{*}$ & $1.14(1.10-1.18)^{*}$ \\
\hline \multicolumn{7}{|l|}{ Gestational period } \\
\hline$<37$ weeks & 31.1 & 43.6 & 83.2 & $1.27(1.23-1.31)^{*}$ & $1.07(1.01-1.14)^{*}$ & $1.04(1.03-1.06)^{*}$ \\
\hline 37 and more & 41.9 & 53.0 & 82.1 & 1 & & 1 \\
\hline \multicolumn{7}{|l|}{ Prenatal appointments (n) } \\
\hline$\leq 3$ & 23.7 & 30.5 & 63.0 & 1 & 1 & 1 \\
\hline 4 to 6 & 29.1 & 41.8 & 73.7 & $1.22(1.17-1.28)^{*}$ & $1.34(1.24-1.46)^{*}$ & $1.15(1.06-1.24)^{*}$ \\
\hline 7 and more & 34.5 & 47.4 & 84.2 & $1.44(1.38-1.50)^{*}$ & $1.72(1.57-1.88)^{*}$ & $1.28(1.18-1.38)^{*}$ \\
\hline \multicolumn{7}{|c|}{ Volume of hospital births (births/year) } \\
\hline Until 1000 & 43.6 & 53.0 & 84.0 & $1.35(1.30-1.41)^{*}$ & $1.18(1.13-1.23)^{*}$ & $1.03(1.01-1.05)^{*}$ \\
\hline 1000 or more & 31.6 & 42.5 & 82.9 & 1 & 1 & 1 \\
\hline \multicolumn{7}{|l|}{ Type of hospital } \\
\hline Public & & & & 1 & 1 & 1 \\
\hline Mixed & & & & $1.06(1.03-1.09)^{*}$ & $1.13(1.09-1.18)^{*}$ & $1.02(1.00-1.03)^{* *}$ \\
\hline
\end{tabular}

${ }^{*} \mathrm{p}<0.001 ;{ }^{* *}$ Does not apply. 
Public hospitals showed a lower proportion of cesarean births, and it is possible to observe the effects of maternal risk factors, such as advanced maternal age, which increases the risk of cesarean births by approximately $45 \%$; multiple pregnancies, to a risk of $121 \%$; and hospitals that perform less than 1000 deliveries a year by $35 \%$.

The risk factors for mixed hospitals were the same as those in public and private hospitals. However, the estimated effects of the variables were intermediate between those of private and public hospitals. Maternal, gestational and newborn characteristics contributed to increase the risk of cesarean sections, but these effects are less pronounced than in public hospitals and more visible than in private hospitals. Multiple pregnancy and seven or more prenatal care visits were the variables that mostly contributed to cesarean sections at mixed hospitals, although high level of mother's education and white newborn skin color increased the risk and showed a higher effect than in the public or private sectors.

The highest attributable risk fraction for the cesarean section was being born in a private hospital, where $41.8 \%$ of the cesarean sections were attributed to this exposure. All of the other exposure variables presented attributable risk fraction lower than 5\%, except for the number of prenatal visits equal or superior to seven, which presented attributable risk fraction of $20.5 \%$ in public hospitals, $18.8 \%$ in mixed hospitals, and $25.3 \%$ in private hospitals (data not shown).

\section{Discussion}

The study demonstrated a growing trend in the proportion of cesarean deliveries, with an estimated increase of 1.4\% per year from 2000 to 2013 in the São Paulo Metropolitan Area. Of all live births in 2009, 53.1\% were by cesarean section, which is higher than the national estimate of 50.1\% [21]. The São Paulo Metropolitan area has multiple hospitals of high complexity, the largest hospital centers and maternity wards in Brazil [22].

The proportion of cesarean sections was higher in private hospitals, as shown in other studies conducted in Brazil [6] [9]. In our study, however, the lowest cesarean proportion was found among women delivering in the public hospitals, followed by those that occurred in mixed hospitals, and it was very high in private hospitals. Similar results have been described in other countries, such as Spain [23], Greece [24] and Australia [25].

In addition to the type of hospital, other variables can be considered as risk factors for cesarean deliveries, such as advanced maternal age, high maternal education, nulliparity, multiple pregnancies, prematurity and seven or more prenatal care visits, which is in accordance with other Brazilian and international studies [2] [8] [11] [12]. Among these factors, the high cesarean proportion among nulliparous women has been a matter of concern in other countries because it is a cumulative factor for the perpetuation of high level of cesarean deliveries because the number of vaginal births reduces after the first cesarean birth [6] [26].

Adolescent age of mothers was found to be a protective factor for cesarean delivery in the three types of hospitals. Even though it was a protective factor, almost $73 \%$ of the births by this age group were delivered by caesarean in private hospitals. Some authors believe that the low percentage of cesarean sections in adolescents is related to the low frequency of obstetric complications in this age group and represent an effort to not interrupt their reproductive life. Other possible explanation is that there are also few instances of tubal ligation followed by cesarean section [16].

Grand multiparous women have also a protective effect against cesarean delivery, but it is difficult to interpret this result. There is no available information on the previous delivery type of multiparous women on the birth certificate in 2009. Previous vaginal births can lead to a future vaginal birth, but previous cesarean sections can predispose mothers to another cesarean. One possible reason is that there is a short delivery labor time among multiparous women, so some of them arrived in hospital in the expulsive period, resulting in vaginal delivery. A meta-analysis found that multiparous women of middle-income countries who had a previous cesarean section showed the highest likelihood of cesarean deliveries [7].

Multivariate analysis by hospital type showed differences in the effect of risk factors for cesarean deliveries. These differences may be the result of different obstetrical care models, differences in available technology [27]; medical practice [6] [8] [28] institutional organization and legal factors [5] [29]. The obstetrical care in private hospitals is exclusively conducted by the doctor who follows pregnant women from prenatal care to delivery, which creates conditions for scheduling the date of delivery. It is known that models incorporating midwives have a higher ratio of vaginal birth [30]. The performance of cesarean sections has been described as a mechanism to optimize the doctor's work, thus ensuring predictability and a shorter time spent in follow-up of the delivery [8] [31]. Moreover, the clinical experience accumulated in the performance of cesarean sections reduces the 
practice of vaginal birth, and causes insecurity in performing that particular type of care [6] [8]. However, there are exceptions. Some obstetricians work with midwives in some private hospitals. This humanized model of obstetrical care prioritizes vaginal delivery, but there is a lack of midwives in the country, less than half that would be necessary for national use of this model [32].

The public hospitals showed the lowest proportion of cesarean births, and the effect of maternal, gestational and newborn risk characteristics are more visible in these hospitals. There is more chance that cesarean deliveries are performed in response to clinical needs. This result may possibly be explained by the obstetric care model in public hospitals, which is multiprofessional. Prenatal care is conducted in primary health care units by a multiprofessional team, while delivery is performed by the doctors and/or obstetric nurses on duty in the hospitals. In addition, the type of delivery does not influence the professional's payment in public hospitals.

Public hospitals are regulated, and there is a limit to the number of paid procedures. There are a set monthly number of cesarean sections for each hospital that are paid for by the Unified Health System [31]. Therefore, the high proportion of cesarean deliveries found in the public network may also be a result of the higher frequency of maternal risk factors in the population who uses the public network. A study conducted in the city of São Paulo found that users of public hospitals presented lower levels of maternal education and higher proportion of very low birth weight $(<1500 \mathrm{~g})$ in relation to private hospitals [22], which partly explains the high values found in the public network. Unfortunately, there are no secondary data available about the frequency of maternal conditions that lead to the performance of cesarean sections, such as the presence of maternal hypertension or infections.

The cesarean proportion found in mixed hospitals presented intermediate values between public and private networks and represents the coexistence of these two birth-care models in these hospitals. However, it was found a higher effect of socioeconomic variables in mixed hospitals, such as newborn skin color and high level of maternal education in comparison to the public and private networks. This result suggests that births by mothers with higher socioeconomic status were paid by private health insurance plans, which operate in accordance with the delivery-care model of private hospitals.

The influence of the hospital's volume of deliveries and location on the proportion of cesarean deliveries was a new finding in Brazil, and these results require further investigation. Hospitals with a low volume of deliveries present a higher proportion of cesarean deliveries. Hospitals with fewer deliveries may present less organization, capacity and skills in terms of caring for pregnant women, which can lead to doctors choosing to perform a cesarean section because they feel more comfortable with this technique [33].

Our study was conducted in the largest metropolitan area of South America with high conurbation, and only $10 \%$ of births took place in hospitals with a low annual volume of deliveries. The increased risk of cesarean sections for births carried out in hospitals located outside the city of the mother's residence could be explained by referrals for high-risk pregnancies, which require complex assistance that is unavailable in their cities of residence. Another possible explanation could be the mothers' choice of hospitals of higher complexity.

There was a statistically significant increase in births by cesarean delivery with the increase of prenatal visits. The attributable risk fraction for seven or more prenatal visits increased the probability of cesarean section by $20 \%$ in the three care networks. Such a finding corroborates other studies that found that pregnant women who are prone to cesarean sections frequently present hypertension and other gestation-related affections that require more careful follow-up and thus result in higher use of health services [8] [10]. Overall, 90\% of women had 7 or more prenatal visits in the private system, which shows that these women have more access to prenatal care than those who use public or mixed hospitals. One study showed that patients of the Brazilian private system had an initial preference for vaginal deliveries of $63.9 \%$, but this preference changed during gestation, declining to $18.6 \%$ [4]. Our results show that only $17.3 \%$ of women had this type of delivery. It seems that instead of prenatal care leading these women to maintain their initial choice, it facilitates the changing of their choice.

This study was performed with secondary data, so there may be some confounding factors that we were not able to control in addition to the absence of explanatory variables for some of the results. Another limitation is the absence of information distinguishing births financed by the public health system from those paid by health insurance plans in mixed hospitals.

\section{Conclusion}

Cesarean rates in São Paulo Metropolitan Area were high, and growing. Delivery in a private hospital is responsible for the majority of cesarean sections; and traditional clinical indications have an important role in the pub- 
lic sector. Health actions to reduce excessive cesarean sections might be directed to pregnant women and care providers especially in the private sector.

\section{References}

[1] Gibbons, L., Belizán, J.M., Lauer, J.A., Betrán, A.P., Merialdi, M. and Althabe, F. (2010) The Global Numbers and Costs of Additionally Needed and Unnecessary Caesarean Sections Performed per Year: Overuse as a Barrier to Universal Coverage. World Health Report, 30.

[2] Villar, J., Valladares, E., Wojdyla, D., Zavaleta, N., Carroli, G., Velazco, A., et al. (2006) Caesarean Delivery Rates and Pregnancy Outcomes: The 2005 WHO Global Survey on Maternal and Perinatal Health in Latin America. Lancet, 367, 1819-1829. http://dx.doi.org/10.1016/S0140-6736(06)68704-7

[3] Henderson, J., McCandlish, R., Kumiega, L. and Petrou, S. (2011) Systematic Review of Economic Aspects of Alternative Modes of Delivery. BJOG, 8, 149-157.

[4] Domingues, R.M.S.M., Dias, M.A.B., Nakamura-Pereira, M., Torres, J.A., D’Orsi, E., et al. (2014) Process of Decision-Making Regarding the Mode of Birth in Brazil: From the Initial Preference of Women to the Final Mode of Birth. Cadernos de Saúde Pública, 30, S1-S16.

[5] Althabe, F. and Belizan, J.F. (2006) Caesarean Section: The Paradox. Lancet, 368, 1472-1473. http://dx.doi.org/10.1016/S0140-6736(06)69616-5

[6] Torres, J.A., Domingues, R.M.S.M., Sandall, J., Hartz, Z., Gama, S.G.N., et al. (2014) Caesarean Section and Neonatal Outcomes in Private Hospitals in Brazil: Comparative Study of Two Different Perinatal Models of Care. Cadernos de Saúde Pública, 30, S1-S12.

[7] Mazzoni, A., Althabe, F., Liu, N., Bonotti, A., Gibbons, L., Sánchez, A. and Belizan, J. (2011) Women’s Preference for Caesarean Section: A Systematic Review and Meta-Analysis of Observational Studies. BJOG, 118, 391-399. http://dx.doi.org/10.1111/j.1471-0528.2010.02793.x

[8] Paim, J., Travassos, C., Almeida, C., Bahia, L. and Macinko, J. (2011) The Brazilian Health System: History, Advances, and Challenges. Lancet, 377, 1778-1797. http://dx.doi.org/10.1016/S0140-6736(11)60054-8

[9] Hopkins, K., de Lima Amaral, E.F. and Mourão, A.N. (2014) The Impact of Payment Source and Hospital Type on Rising Cesarean Section Rates in Brazil, 1998 to 2008. Birth, 41, 169-177. http://dx.doi.org/10.1111/birt.12106

[10] World Health Organization (1985) Appropriate Technology for Birth. Lancet, 2, 436-437.

[11] Padua, K.S., Osis, M.J.D., Faundes, A., Barbosa, A.H. and Moraes, O.B. (2010) Factors Associated with Cesarean Sections in Brazilian Hospitals. Revista de Saúde Pública, 44, 70-79.

[12] Barros, A.J.D., Santos, I.S., Matijasevich, A., Domingues, M.R., Silveira, M., Barros, F.C. and Victora, C.G. (2011) Patterns of Deliveries in a Brazilian Birth Cohort: Almost Universal Cesarean Sections for the Better-Off. Revista de Saúde Pública, 45, 635-643. http://dx.doi.org/10.1590/S0034-89102011005000039

[13] Behague, D.P., Victora, C.G. and Barros, F.C. (2002) Consumer Demand for Caesarean Sections in Brazil: Informed Decision Making, Patient Choice or Social Inequality? A Population Based Birth Cohort Study Linking Ethnographic and Epidemiological Methods. BMJ, 324, 942-945. http://dx.doi.org/10.1136/bmj.324.7343.942

[14] Teixeira, C., Correia, S., Victora, C.G. and Barros, H. (2013) The Brazilian Preference: Cesarean Delivery among Immigrants in Portugal. PLoS ONE, 8, e60168. http://dx.doi.org/10.1371/journal.pone.0060168

[15] Potter, J.E., Hopkins, K., Faúndes, A.M.D. and Perpétuo, I. (2008) Women’s Autonomy and Scheduled Cesarean Sections in Brazil: A Cautionary Tale. Birth, 35, 33-40. http://dx.doi.org/10.1111/j.1523-536X.2007.00209.X

[16] Carvalho, L.E.C., Osis, M.J.D., Cecatti, J.G., Bento, S.F. and Manfrinati, M.B. (2007) Voluntary Surgical Sterilization in Greater Metropolitan Campinas, São Paulo State, Brazil, before and after Legal Regulation of the Procedure. Cadernos de Saúde Pública, 23, 2906-2916. http://dx.doi.org/10.1590/S0102-311X2007001200012

[17] MS. Brazilian System of Health Information. Ministry of Health. Accessed on 20 August 2015. http://datasus.saude.gov.br/informacoes-de-saude/tabnet/rede-assistencial

[18] MS. Brazilian System of Health Information. Ministry of Health. Accessed on 6 October 2015. http://tabnet.datasus.gov.br/cgi/tabcgi.exe?sinasc/cnv/nvsp.def

[19] Coutinho, L.M., Scazufca, M. and Menezes, P.R. (2008) Methods for Estimating Prevalence Ratios in Cross-Sectional Studies. Revista de Saúde Pública, 42, 992-998. http://dx.doi.org/10.1590/S0034-89102008000600003

[20] Spiegelman, D., Hertzmark, E. and Wand, C. (2007) Point and Interval Estimates of Partial Population Attributable Risks in Cohort Studies: Examples and Software. Cancer Causes Control, 18, 571-579. http://dx.doi.org/10.1007/s10552-006-0090-y

[21] Ministry of Health (Brazil). Live Birth Information Systems Brazil. Accessed on 18 March 2014. 
http://www2.datasus.gov.br/DATASUS/index.php?area=0201

[22] Silva, Z.P., Almeida, M.F., Ortiz, L.O., Alencar, G.P., Alencar, A., et al. (2010) Early Neonatal Mortality According to Level of Hospital Complexity in Greater Metropolitan São Paulo, Brazil. Cadernos de Saúde Pública, 26, 123-134. http://dx.doi.org/10.1590/S0102-311X2010000100013

[23] Salvador, J., Cano-Serral, G., Rodriguez-Sanz, M., Lladonosa, A. and Borrell, C. (2009) Inequalities in Caesarean Section: Influence of the Type of Maternity Care and Social Class in an Area with a National Health System. Journal of Epidemiology and Community Health, 63, 259-261. http://dx.doi.org/10.1136/jech.2007.071977

[24] Mossialos, E., Allin, S., Karras, K. and Davaki, K. (2005) An Investigation of Caesarean Sections in Three Greek Hospitals the Impact of Financial Incentives and Convenience. The European Journal of Public Health, 15, 288-295. http://dx.doi.org/10.1093/eurpub/cki002

[25] Einarsdóttir, K., Haggar, F., Pereira, G., Leonard, H., de Klerk, N., Stanley, F.J. and Stock, S. (2013) Role of Public and Private Funding in the Rising Caesarean Section Rate: A Cohort Study. BMJ Open, 3, e002789. http://dx.doi.org/10.1136/bmjopen-2013-002789

[26] Menacker, F., Hamilton, B.E., Howell, S., Johnston, T. and Macleod, S.L. (2010) Recent Trends in Cesarean Delivery in the United States. NCHS Data Brief, No. 35, 1-8.

[27] Hotimsky, S.N., Rattner, D., Venancio, S.I., Bogus, C.M. and Miranda, M.M. (2002) Childbirth as I See It.... or the Way I Wish It Was? Expectations of Pregnant Women towards Childbirth and Obstetric Care in the Public Health Care System. Cadernos de Saúde Pública, 18, 1303-1311. http://dx.doi.org/10.1590/S0102-311X2002000500023

[28] Hopkins, K. (2000) Are Brazilian Women Really Choosing to Deliver by Cesarean? Social Science \& Medicine, 51, 725-740. http://dx.doi.org/10.1016/S0277-9536(99)00480-3

[29] D’Orsi, E., Chor, D., Giffin, K., Angulo-Tuesta, A., Barbosa, G.P., Gama, A.S., et al. (2005) Factors Caesarean Associates and Quality of the Attention to the Childbirth in the City of Rio de Janeiro. Revista de Saúde Pública, 39, 646654.

[30] Renfrew, M.J., McFadden, A., Bastos, M.H., Campbell, J., Channon, A.A., et al. (2014) Midwifery and Quality Care: Findings from a New Evidence Informed Framework for Maternal and Newborn Care. Lancet, 384, 1129-1145. http://dx.doi.org/10.1016/S0140-6736(14)60789-3

[31] Riesco, M.L.G. (2014) Birth in Brazil “in Time”: A Matter of Hierarchy in Birthcare Interventions? Cadernos de Saúde Pública, 30, S1-S31.

[32] Narchi, N.Z., Cruz, E.F. and Gonçalves, R. (2013) The Role of Midwives and Nurse-Midwives in Promoting Safe Motherhood in Brazil. Ciência \& Saúde Coletiva, 18, 1059-1068. http://dx.doi.org/10.1590/S1413-81232013000400019

[33] Faúndes, A., Pádua, K.S., Osis, M.J., Cecatti, J.G. and Sousa, M.H. (2004) Brazilian Women and Physicians’ Viewpoints on Their Preferred Route of Delivery. Revista de Saúde Pública, 38, 488-494. http://dx.doi.org/10.1590/S0034-89102004000400002 